\title{
Performance of Chitosan/Glycerol Phosphate Hydrogel as a Support for Lipase Immobilization
}

\author{
Rafael Matsumoto Pereira ${ }^{a}$, Grazielle Santos Silva Andrade ${ }^{a}$ Heizir Ferreira De Castro ${ }^{b}$, \\ Maria Gabriela Nogueira Campos ${ }^{a *}$ \\ ${ }^{a}$ Instituto de Ciência e Tecnologia, Universidade Federal de Alfenas, CEP 37715-400, \\ Poços de Caldas, MG, Brazil \\ ${ }^{b}$ Escola de Engenharia de Lorena, Universidade de São Paulo, CEP 12602-810, Lorena, SP, Brazil
}

Received: January 17, 2017; Revised: May 09, 2017; Accepted: May 21, 2017

\begin{abstract}
A biocompatible and biodegradable hybrid chitosan/glycerol phosphate hydrogel (CS-GP) was prepared and evaluated as support for enzyme immobilization. In this work a lipase sn-1,3 specific from Rhizopus oryzae was physically immobilized in CS-GP by adsorption (PA) and in CS-GP modified chemically with glutaraldehyde (CS-GP-GA) by covalent attachment (CA). The matrices (pure and chemically modified) and immobilized lipases were characterized by scanning electron microscopy (SEM), Fourier Transform Infrared Spectroscopy (FTIR) and thermogravimetric (TG) analysis. Moreover, a comparative study between free and immobilized lipase was provided in terms of $\mathrm{pH}$, temperature, kinetic parameters and thermal stability. The catalytic properties of biocatalysts were assayed in olive oil hydrolysis. The maximum activities were found at $60{ }^{\circ} \mathrm{C} / \mathrm{pH} 8.5$ and $50 \circ \mathrm{C} / \mathrm{pH} 7.5$ for lipase immobilized by PA and CA, respectively. Both immobilization process turned biocatalysts highly active, since they were stable for 120 days at low $\left(-10{ }^{\circ} \mathrm{C}\right)$ temperatures and around 2 -fold more stable than free lipase at $60 \circ \mathrm{C}$ (high temperature). Thus, results revealed the potential application of chitosan/glycerol phosphate hydrogel (CS-GP) as matrix for lipase immobilization. Nevertheless, better performance was achieved when the lipase was immobilized by covalent attachment.
\end{abstract}

Keywords: lipase, immobilization, chitosan, glycerol phosphate, hydrogel

\section{Introduction}

Hydrogels are three-dimensional polymeric structures able to absorb large quantities of water or biological fluids. Based on this, hydrogels are often classified into three categories depending on the nature of their network, namely entangled networks, covalently crosslinked networks and networks formed by secondary interactions. According to the literature, chitosan is one of the main compounds used in the synthesis of hydrogels ${ }^{1}$. The development of chitosan hydrogel has been an area drawing intensive investigation and a large number of works have been reported on chitosan hydrogel and its potential use in various applications $s^{2-6}$. The biochemical properties and the three-dimensional networks of chitosan hydrogel offer them wide applications in biomedical field including local drug delivery and tissue engineering ${ }^{7}$.

Several polymers have been used to prepare chitosan hybrid hydrogels, such as gelatin, collagen, carrageenan, alginate, polyvinyl alcohol (PVA), and carboxy-methylcellulose (CMC). The polyelectrolyte complexes of chitosan are formed with the purpose of obtaining more versatile hydrogels with different chemical and physical structures, which can improve your performance in specific industrial applications, such as medical and pharmaceutical ${ }^{1,8}$.
Among of the chitosan hybrid hydrogels, chitosan/glycerol phosphate hydrogel has received strong interest in medical and pharmaceuticals applications ${ }^{7}$. In recent years, chitosan/ GP gels have already been used for repairing cartilage, bone and nerves; and also, functioned as injectable vehicles for delivering different drugs or bioactive molecules ${ }^{9}$. Glycerol phosphate is an organic compound naturally found in the body has been used as a catalyst to cause a sol-to-gel transition in chitosan solutions at physiological $\mathrm{pH}$ and temperature ${ }^{7}$.

The interest in modifying chitosan using different activation agents, and the use of polyelectrolyte complexes, have arisen recently mostly for applications in the field of enzyme immobilization. In recent time, various natural polymers, such as chitosan, have received great importance for immobilization which having excellent properties like biodegradability, eco-friendliness and biocompatibility for biomolecules ${ }^{10}$.

Immobilization of enzymes plays an import role within applied biotechnology. The main reason for immobilizing enzymes is the ability to isolate the biocatalyst from the reaction product and reuse it in order to increase productivity ${ }^{11,12}$. Among the available enzymes, lipases (triacylglycerol alkyl hydrolases, EC 3.1.1.3) are versatile biocatalysts used in several industrial processes under aqueous or organic media.

* e-mail: maria.campos@unifal-mg.edu.br 
Thus, lipase immobilization has been widely studied, mainly due to its industrial importance ${ }^{13}$.

In this context, this work investigates the biocompatible of chitosan/glycerol phosphate hydrogel (CS-GP) to immobilize a commercial food grade lipase sn-1,3 specific from Rhizopus oryzae. This lipase was chosen based on its potential previously identified to synthesize important products, such as structured lipids ${ }^{14}$. The lipase was immobilized on CS-GP by physical adsorption (PA) and covalent attachment (CA). The properties of both CS-GP support and immobilized derivatives were evaluated by Scanning electron microscopy (SEM), Fourier transform infrared spectroscopy (FTIR) and termogravimetry (TG). The influence of the temperature and $\mathrm{pH}$ on the biocatalyst activities was assessed by surface response methodology. Under the established conditions, the kinetic parameters and thermal stability of the immobilized derivatives were also determined and compared with those attained by the free lipase. To our knowledge, this is the first report of the use of chitosan/glycerol phosphate hydrogel as support for immobilizing microbial lipase.

\section{Materials and Methods}

A commercial food grade lipase from Rhizopus oryzae (L036P, Biocatalysts, Cardiff, England) in a crude form was used without further purification. High molecular weight chitosan (degree of deacetylation above 75\%) and glycerol phosphate disodium salt were purchased from SigmaAldrich (St. Louis-USA). Glutaraldehyde 25\% was used as cross-linker. Commercial olive oil with acidity of $0.5 \%$ $\left(\right.$ Carbonell $^{\circledR}$ ) was purchased in a local market and used for hydrolytic activity experiments. Arabic gum was purchased from Synth/Brazil.

\subsection{Preparation of CS-GP based supports}

The CS-GP supports was prepared by dissolving chitosan $(0.6 \mathrm{~g})$ in $9 \mathrm{~mL}$ of hydrochloric acid $\left(0.1 \mathrm{~mol} \mathrm{~L}^{-1}\right)$ followed by addition of $1.0 \mathrm{~mL}$ of disodium salt glycerol phosphate solution $\left(0.560 \mathrm{~g} \mathrm{~mL}^{-1}\right)$ drop by drop under stirring. The product (CS-GP hydrogel) was then autoclaved at $121^{\circ} \mathrm{C}$ for $15 \mathrm{~min}$, frozen in liquid nitrogen and lyophilized at $-20^{\circ} \mathrm{C}$. Finally, the support was grounded to acquire powder form (CS-GP powder).

\subsection{Lipase immobilization by physical adsorption (PA)}

Initially, the CS-GP powder was soaked in anhydrous ethanol atproportion of $1: 1.5\left(\mathrm{w} \mathrm{v}^{-1}\right)$ under stirring (50 rpm) for $6 \mathrm{~h}$ at room temperature. After that period, ethanol excess was removed and lipase was addedin the ratio of $1: 4\left(\mathrm{w} \mathrm{w}^{-1}\right)$ (enzyme:support) together with buffer phosphate $\mathrm{pH} 7.0$ (5 mmol L $\left.\mathrm{L}^{-1}\right)$ at a ratio of 1:60 ( $\left.\mathrm{w} \mathrm{w}^{-1}\right)$ (support:solution). The system was maintained in contact for $18 \mathrm{~h}$ at room temperature under stirring ( $50 \mathrm{rpm})$. Finally, the immobilized biocatalyst was filtered under vacuum and stored at $4{ }^{\circ} \mathrm{C}$.

\subsection{Lipase immobilization by covalent attachment (CA)}

The CS-GP powder was added to buffer phosphate $\mathrm{pH} 7.0\left(0.2 \mathrm{~mol} \mathrm{~L}^{-1}\right)$ at a ratio of $1: 1.2\left(\mathrm{w} \mathrm{v}^{-1}\right)$. Then, glutaraldehyde solution (25\%) was added at a ratio of $1: 1.7$ $\left(\mathrm{w} \mathrm{v}^{-1}\right)$ (support:solution). The system was stirred at $50 \mathrm{rpm}$ for 1 hour, filtered and washed with distilled water to remove the unbound glutaraldehyde (GA) and dried under vacuum to yield the CS-GP-GA (chitosan/glycerol phosphate hydrogel with glutaraldeyde) powder. After thar, buffer phosphate $\mathrm{pH} 7.0\left(5 \mathrm{mmol} \mathrm{L}^{-1}\right)$ was added at a ratio of 1:60 $\left(\mathrm{w} \mathrm{w}^{-1}\right)$ (support:solution). The system was maintained in contact for $18 \mathrm{~h}$ at room temperature under stirring $(50 \mathrm{rpm})$. Finally, the immobilized biocatalyst was filtered under vacuum and stored at $4{ }^{\circ} \mathrm{C}$.

\subsection{Support and biocatalyst characterization}

\subsubsection{Scanning Electron Microscopy}

Superficial morphologies of the CS-GP, CS-GP-GA and immobilized lipase were observed by Scanning Electron Microscopy (SEM) (Topcon/Singapore). The samples were coated with a gold film thickness of $16 \mathrm{~nm}$ (Bal-tec/USA).

\subsubsection{Fourier transform infrared spectroscopy}

Fourier transform infrared (FTIR) spectra were obtained in transmission mode on a FT-IR spectrometer Agilent Cary 630 (Agilent Technlogies/EUA) without further sample preparation.

\subsubsection{Thermogravimetry}

Thermal stability and weight loss profiles were determined using a thermogravimetric analysis (TG) in the STA 449F3 Calorimeter (Netzsch/Germany) under Argon atmosphere in the temperature range from $30^{\circ} \mathrm{C}$ to $500^{\circ} \mathrm{C}$, heating rate of $10^{\circ} \mathrm{C} \mathrm{min}^{-1}$ and mass $5.00 \pm 0.50 \mathrm{mg}$.

\subsection{Determination of optimal enzymatic activities and kinetic parameters}

The effect of $\mathrm{pH}$ and temperature on the hydrolytic activities of free and immobilized lipases was assessed according to a $2^{2}$ full factorial design with three replicates at the center points. Star points were added to the experimental design for free and lipase immobilized by $\mathrm{CA}$ in order to 
compose second order model. The activities were assayed by the hydrolysis of olive oil emulsion at a fixed proportion oil/water $1: 1^{15}$. The experimental design results were analyzed using Statistica version 7 (StatSoft Inc., USA).

The influence of substrate concentration (Carbonell ${ }^{\circledR}$ olive oil) on the hydrolytic activities was also analyzed in the hydrolysis assay varying the proportion of oil in the emulsion from 5 to $70 \%\left(\mathrm{v} \mathrm{v}^{-1}\right)$. Michaelis-Menten constant $\left(\mathrm{K}_{\mathrm{m}}\right)$ and the maximum velocity $\left(\mathrm{V}_{\max }\right)$ were calculated using OriginPro version 8 (Originlab Corporation).

\subsection{Thermal and storage stability}

Determination of the denaturation constant $\left(\mathrm{k}_{\mathrm{d}}\right)$, halflife time $\left(\mathrm{t}_{1 / 2}\right)$ and the residual activity after differents time intervals $(15,30,60,90,120$ and $150 \mathrm{~min})$ was made by incubated $1.0 \mathrm{~mL}$ of the free lipase solution $\left(0.5 \mathrm{mg} \mathrm{mL}^{-1}\right)$ or $0.1 \mathrm{~g}$ of immobilized lipase in the presence of $4 \mathrm{~mL}$ of buffer phosphate $\mathrm{pH} 7.0\left(0.1 \mathrm{~mol} \mathrm{~L}^{-1}\right)$ at $60^{\circ} \mathrm{C}$ and then cooled in an ice bath. The residual hydrolytic activity was calculated by the olive-oil emulsion method (as described above) and the parameters $\mathrm{k}_{\mathrm{d}}$ and $\mathrm{t}_{1 / 2}$ by Eq. 1 and Eq. 2, respectively, assuming a first order thermal denaturation.

$$
\begin{aligned}
\mathrm{A} & =\mathrm{A}_{0} \mathrm{e}^{-\mathrm{k} d \mathrm{t}} \\
\mathrm{t}_{1 / 2} & =\frac{\ln 0.5}{-\mathrm{k}_{\mathrm{d}}}
\end{aligned}
$$

where $\mathrm{A}$ is the hydrolytic activity at time $(\mathrm{t}), \mathrm{A}_{0}$ is the hydrolytic activity at time $t_{0}, k_{d}$ is the denaturation rate $\left(\mathrm{min}^{-1}\right), \mathrm{t}$ is incubation time ( $\left.\mathrm{min}\right)$.

The samples of free and immobilized lipase was storage in low temperature $\left(-10^{\circ} \mathrm{C}\right)$ and storage stability was evaluate. Each 30 days the lipase activity was evaluate in a maximum period of 120 days.

\section{Results and Discussion}

\subsection{Preparation of CS-GP support and immobilization efficiency}

Chitosan hydrogels have been prepared with a variety of different geometries and formulations. In each preparation, the polymer binding is accomplished either by non covalent physical association, such as secondary forces (hydrogen, ionic, or hydrophobic bonding) and physical entanglements, or by covalent cross-linked chemical association ${ }^{7}$. Figures 1 and 2 show the hypothetical representation of the mechanism for the immobilization of lipase on CS-GP hydrogel by physical adsorption (PA) and covalent attachment (CA), respectively. Chitosan dissolves in acidic environments via protonation of its amine groups $\left(\mathrm{NH}_{3}^{+}\right)$that reacts with negative charge of oxygen from $\mathrm{GP}\left(\mathrm{PO6}^{5-}\right)$ at $\mathrm{pH}<6.5$. The chitosan-glycerol phosphate electrostatic attraction via ammonia and phosphate groups is one of the effective interactions responsible for the sol-to-gel transition. It is proposed that for immobilization process by physical adsorption lipase is entrapped between the ionic bonds of chitosan and GP, resulting in the structure as shown in Figure 1. By covalent attachment, CS-GP was activated with glutaraldehyde to incorporate aldehyde groups on the support surface by reacting with the amino groups of CS-GP, aiming to render adequate functional groups to the covalent binding with the enzyme (Figure 2). The chemical activation resulted in bindings between the free aldehyde groups and amino groups $\left(\mathrm{NH}_{2}\right)$ of the lipase. In addition, lipase could still be trapped in the interstitial spaces formed between the polymer and glutaraldehyde.

Free lipase showed average activity of $11276.9 \pm 236.4$ $\mathrm{U} \mathrm{g}^{-1}$. According to the immobilization procedures, the covalent attachment provided better performance (average activity of $439.8 \pm 11.2 \mathrm{U} \mathrm{g}^{-1}$ ) in comparison with the lipase

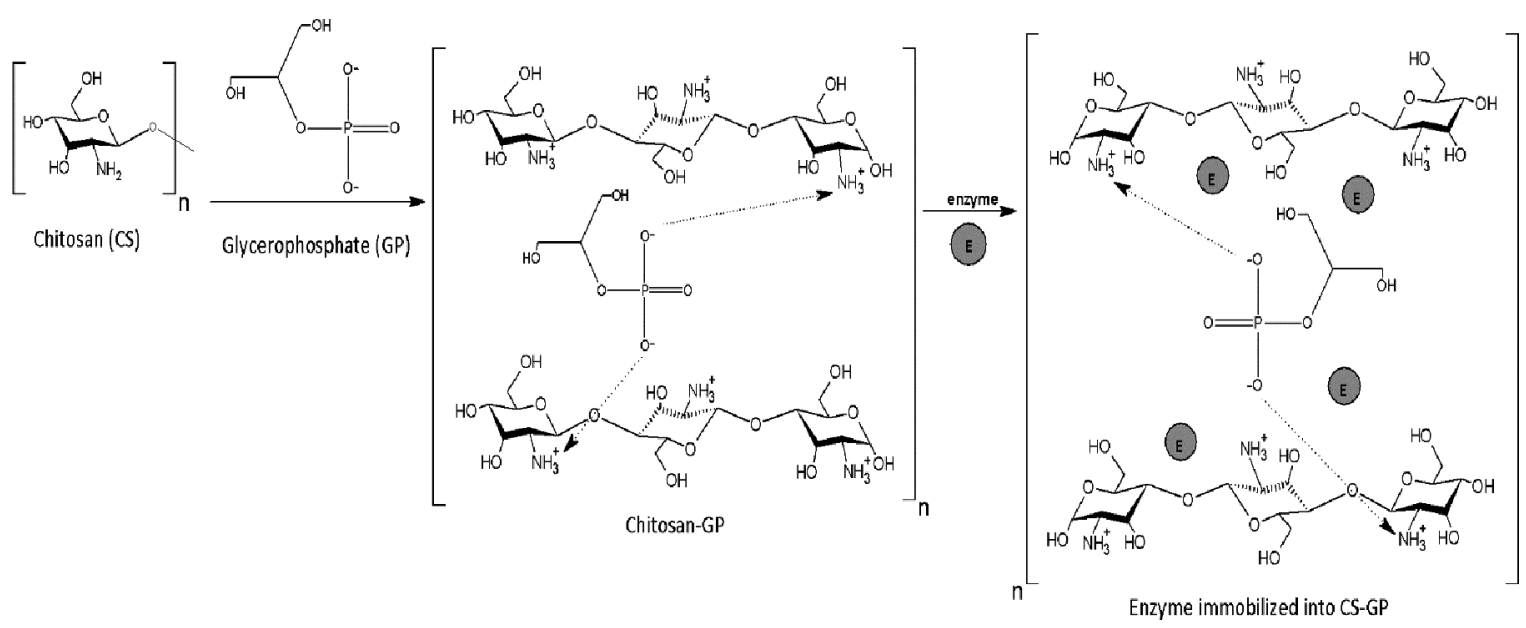

Figure 1. Hypotetic representation of CS-GP matrix formation and lipase immobilization by physical adsorption. 

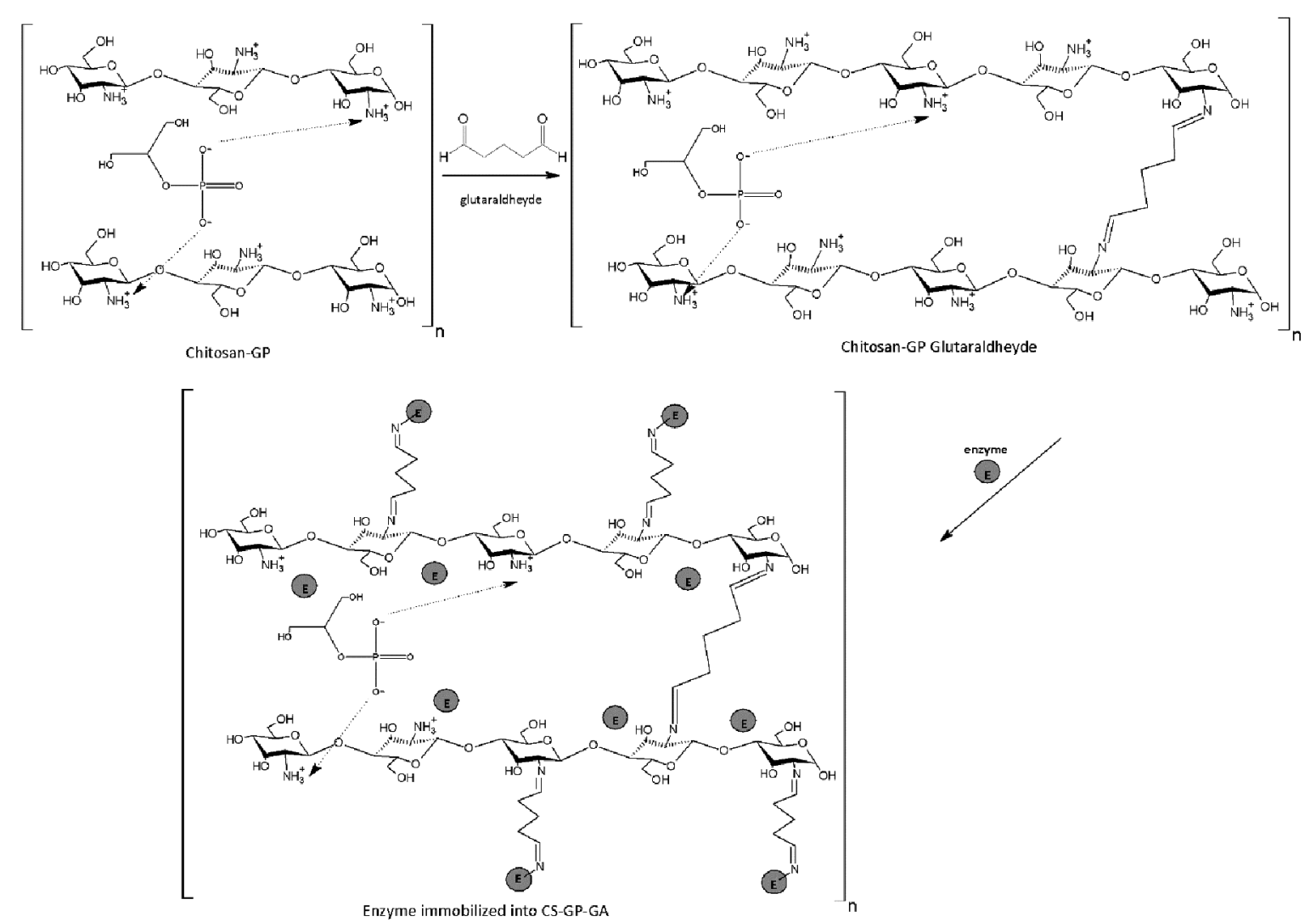

Figure 2. Hypotetic representation of CS-GP matrix formation and and lipase immobilization by covallent atachment.

immobilized by physical adsorption, which revealed average activity of $406.3 \pm 15.8 \mathrm{U} \mathrm{g} \mathrm{g}^{-1}$. Such results indicated that the use of glutaraldehyde slight increased the linkage between the enzyme and the support.

\subsection{Characterization of CS-GP supports and the immobilized lipase preparations}

\subsubsection{FTIR}

The efficiency of both immobilization procedures in relation to the lipase incorporation on the support was assessed by Fourier transformed infrared spectroscopy (FTIR). FTIR technique was used to identify and characterize the chemical bonds and functional groups based on the principle that each type of bond has a characteristic absorption wavelength represent as an upward peak on a charted spectrum ${ }^{16}$. Figure $3 \mathrm{a}$ and Figure $3 \mathrm{~b}$ show that the spectra of CS-GP and CS-GP-GA supports. Both materials exhibited bands at $3000-3500 \mathrm{~cm}^{-1}$ corresponding to stretching vibration of the $\mathrm{OH}$ group suggesting the presence of intramolecular water $^{17,18}$. Other common bands occurred between 1900$1200 \mathrm{~cm}^{-1}$ due to the presence of the amine group in the material ${ }^{19,20}$. The band at $1100-900 \mathrm{~cm}^{-1}$ is probably due to the binding of polysaccharides characteristic of $\mathrm{CO}^{21}$. Such profiles were expected since both materials have amino or amide linkage in their composition. Nevertheless, according to Beppu et al. (2007), the CS-GA crosslinking shows an increase in the absorption at $1655 \mathrm{~cm}^{-1}$ due to imine bonds $(\mathrm{N}=\mathrm{C})^{22}$. In addition, ethylenic and free-aldehydic shoulders at 1562 and $1720 \mathrm{~cm}^{-1}$ were observed relatively to the intensity of other peaks ${ }^{22}$. An increase in the $\mathrm{C}-\mathrm{H}$ stretch bond at $2936 \mathrm{~cm}^{-1}$ and a decrease in the peak at $1100 \mathrm{~cm}^{-1}$ were also observed by these authors, indicating the presence of aliphatic amino groups ${ }^{22}$.

The immobilization of lipase by PA and CA can be confirmed by the presence of characteristics peaks of lipase on these spectra (Fig. 3b). Free enzyme displayed a typical spectrum of proteins with bands associated to their characteristic amide group (CONH). The band of 1700-1600 $\mathrm{cm}^{-1}$ is related to the amide I vibration and $\mathrm{C}=\mathrm{O}$ carboxylic $\operatorname{acid}^{17,18}$ (Fig 3b). The band in the range of $1600-1510 \mathrm{~cm}^{-1}$ present in the lipase immobilized by physical absorption spectrum, but not found in the free lipase and CS-GP spectra, refers to the $\mathrm{N}-\mathrm{H}$ bond with contribution of $\mathrm{C}=\mathrm{N}$ vibrational ${ }^{23-25}$, suggesting an interaction between the enzyme and support ( $\mathrm{NH}$ bending) ${ }^{19,21}$.

\subsubsection{SEM}

Morphological evidences also suggested interactions among CS, GP, GA and lipase. Figure 4 (a-d) shows the 


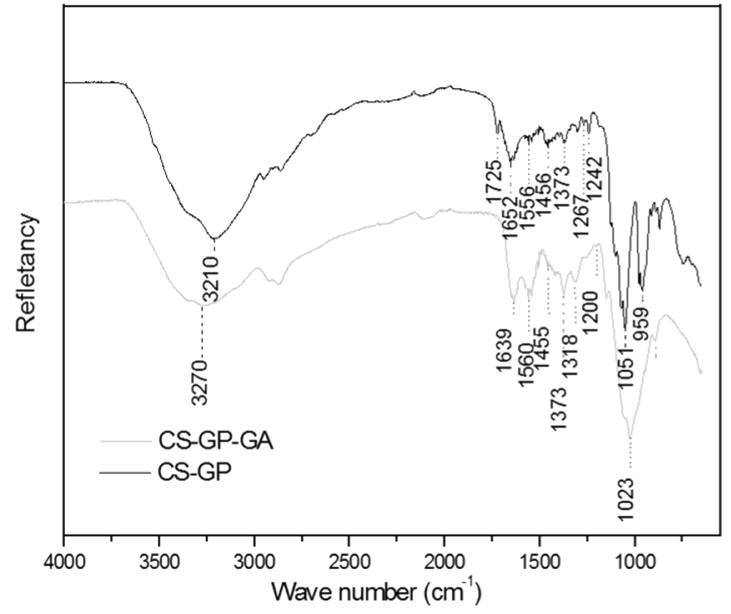

(a)

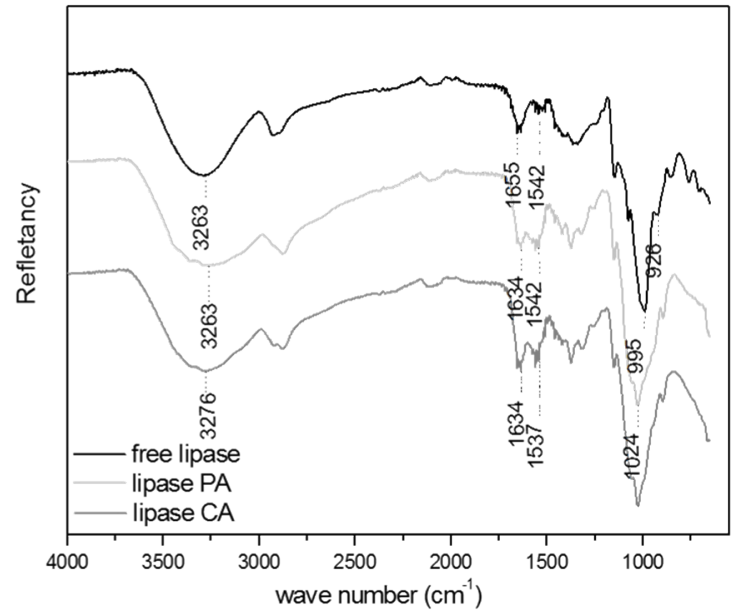

(b)

Figure 3. (a) Fourier Transformed Infrared Specta of (black) chitosan-glycerol phosphate support, and (grey) chitosan-glycerol phosphate crosslinked with glutaraldehyde. (b) Fourier Transformed Infrared Specta of (black) free lipase, (light grey) system lipase immobilized by physical absorption, and (dark grey) system lipase immobilized by covalent attachement.

SEM micrographs of the CS-GP and CS-GP-GA supports and lipase immobilized by PA and CA. Figure 4a shows CS-GP micrograph. Sheet-shaped particles can be observed, while CS-GP-GA micrograph (Fig. 4b) show a dense and compact structure with some particles attached. It may be inferred that cross-linking with glutaraldehyde reduced the superficial porosity of the CS-GP-GA and increased the materials' interactions.

Comparing both immobilized derivatives (Fig. 4c and 4d), it can be observed that the system lipase immobilized by PA (on CS-GP support) shows more superficial pores than the system lipase immobilized on CS-GP-GA (by CA). Such difference was expected, since the structure of CS-GP-GA support is crosslinked by the activation with GA and showed smaller and fewer pores.

\subsubsection{TG}

Thermal stability of supports and the immobilized samples was evaluated by thermogravimetric analysis. The TG curves and their derivatives (DTG) of all samples are displayed in Figure 5a-d. The first mass loss occurred around $100-150^{\circ} \mathrm{C}$ and is attributed to the evaporation of superficial water and degradation of low molecular weight species, such as amino acids, peptides and oligomers ${ }^{26}$.

By analyzing thermal stability of the supports without enzyme (Fig. 5a and 5b), it can be observe that the presence of glutaraldehyde has altered the mechanism of degradation of the CS-GP-GA compared to the CS-GP. Only 3\% of mass was lose by CS-GP-GA around $300-350{ }^{\circ} \mathrm{C}$, while CS-GP lost $21 \%$ at this same temperature range. The mass loss at around $300^{\circ} \mathrm{C}$ is due to the polymer degradation and removal of intramolecular water. It can also be attributed to the dehydration of the saccharide rings and depolymerization ${ }^{27}$.

On the other hand, a mass loss of $22 \%$ was observed for the crosslinked support (CS-GP-GA) at $475^{\circ} \mathrm{C}$, which can be attributed to the polymer degradation. Nevertheless, the residual mass at $500^{\circ} \mathrm{C}$ for CS-GP and CS-GP-GA were 65 and $75 \%$, respectively. These results suggest that the presence of glutaraldehyde increased the stability of the support.

Similar behavior was observed comparing the lipases immobilized by PA and CA (Fig. 5d an 5e). The mass loss of the system lipase immobilized by $\mathrm{PA}$ at $300^{\circ} \mathrm{C}$ was $39 \%$, while the system lipase immobilized by PA lost only $3 \%$ at this temperature. The reduced mass loss of the system lipase immobilized by PA can be due to the three-dimensional structure of CS-GP-GA, which made difficult its decomposition and protected the lipase from degradation. In contrast, free lipase lost more than half of its mass at this temperature $(52 \%$, Fig. $5 \mathrm{c})$. Therefore, both systems increased thermal stability of the immobilized lipase at $300^{\circ} \mathrm{C}$.

The residual mass at $500^{\circ} \mathrm{C}$ for free lipase, lipase immobilized by PA and lipase immobilized by CA were 25 , 45 and $55 \%$, indicating that the immobilization procedures increased thermal stability of lipase and the presence of glutaraldehyde made the system more thermally stable.

\subsection{Kinetics properties of the lipases immobilized by $P A$ and $C A$}

The enzyme kinetics parameters $\mathrm{K}_{\mathrm{m}}$ and $\mathrm{V}_{\max }$ were measured from nonlinear regression technique aiming to determine the catalytic effectiveness of the immobilized lipases in relation to the free lipase. The apparent $\mathrm{V}_{\max }$ 


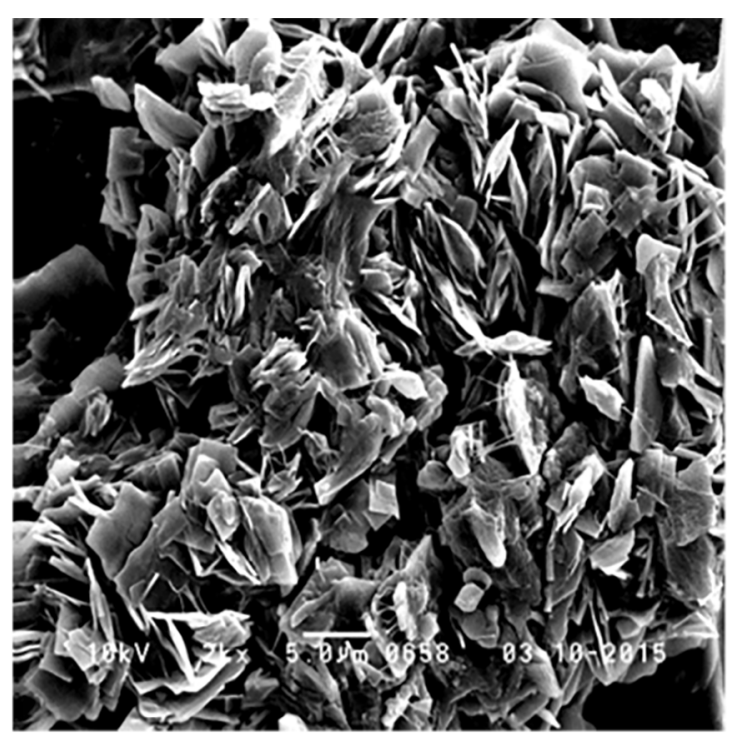

(a)

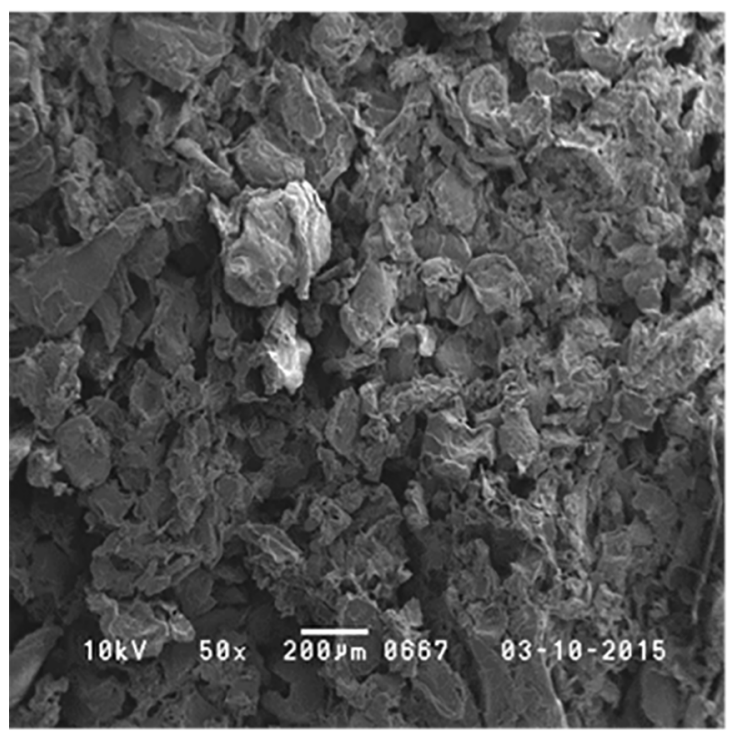

(c)

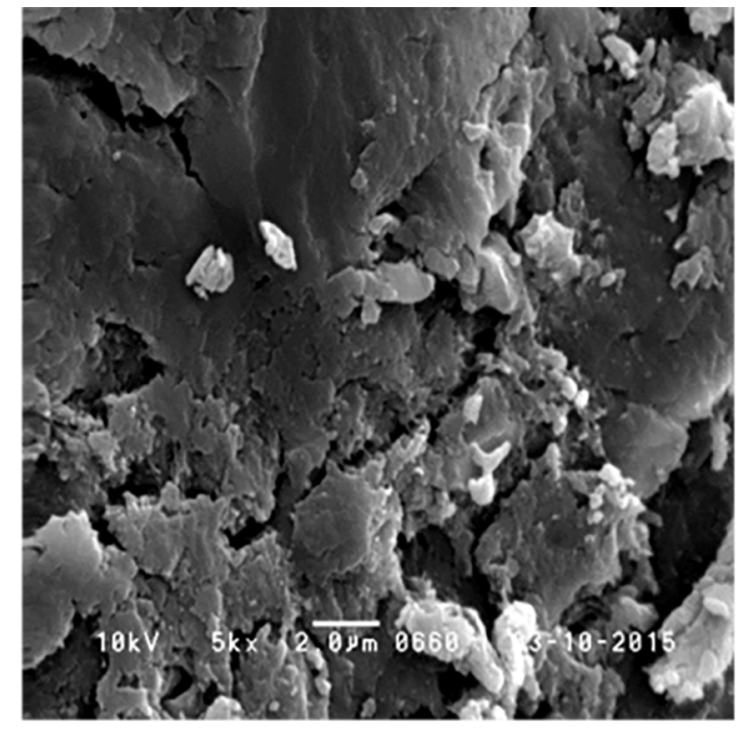

(b)

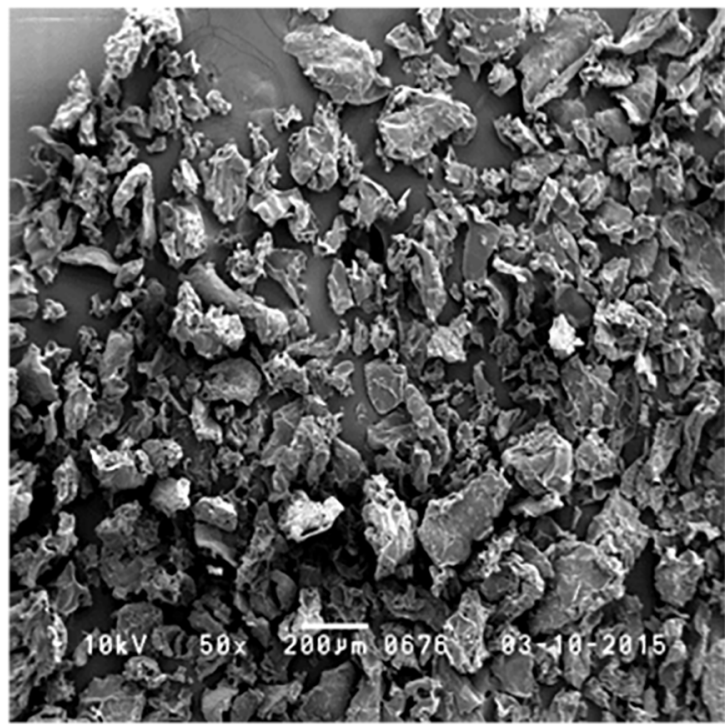

(d)

Figure 4. Scanning Electron Microscopy images of (a) CS-GP, (b) CS-GP-GA, (c) lipase immobilized by physical absorption (PA) and (d) lipase immobilized by covalent attachement (CA).

value indicated the maximum reaction rate and the $\mathrm{K}_{\mathrm{m}}$ value indicated the substrate affinity and enzyme conformational changes, while the catalytic efficiency $\left(\mathrm{V}_{\max } / \mathrm{K}_{\mathrm{m}}\right)$ indicated the overall cumulative effect of $\mathrm{V}_{\text {max }}$ and $\mathrm{K}_{\mathrm{m}}$ on enzyme activity ${ }^{28}$. The activities of free and immobilized lipases at different substrate concentrations were determined and the kinetic constants were calculated (Table 1).

Free lipase showed a value of $\mathrm{Km} 1153.1 \pm 239.8 \mathrm{mM}$ and lipase immobilized by PA and CA showed values of $2806.4 \pm 953.5 \mathrm{mM}$ and $771.0 \pm 245.7 \mathrm{mM}$, respectively. These results reveal that the affinity of the lipase immobilized by PA towards the substrate decreased 2.4 times while the lipase immobilized by $\mathrm{CA}$ enhanced the affinity 1.5 times. In case of immobilization by CA, probably, the covalent attachment aids the scattering of lipases into the support matrix, so that higher substrate concentration was experienced around the immobilized lipase $\mathrm{e}^{29}$. Otherwise, a possible explanation for higher $\mathrm{K}_{\mathrm{m}}$ value determined on the lipase immobilized by PA may be the modifications in the zeta potential, since CS-GP particles without crosslink with GA can change the 


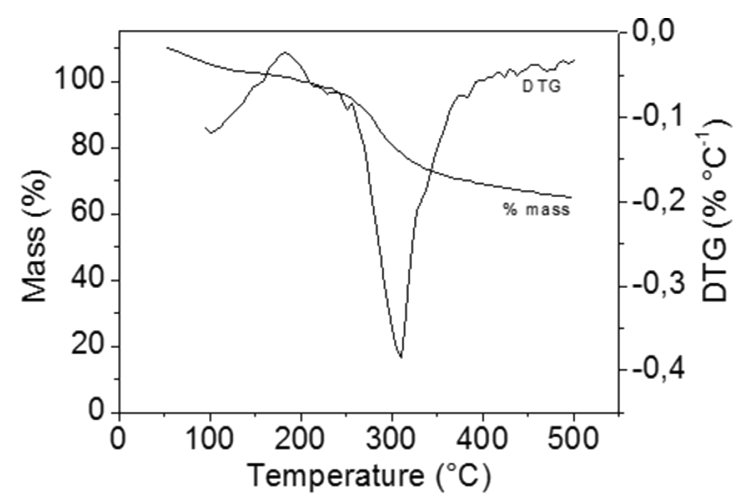

(a)

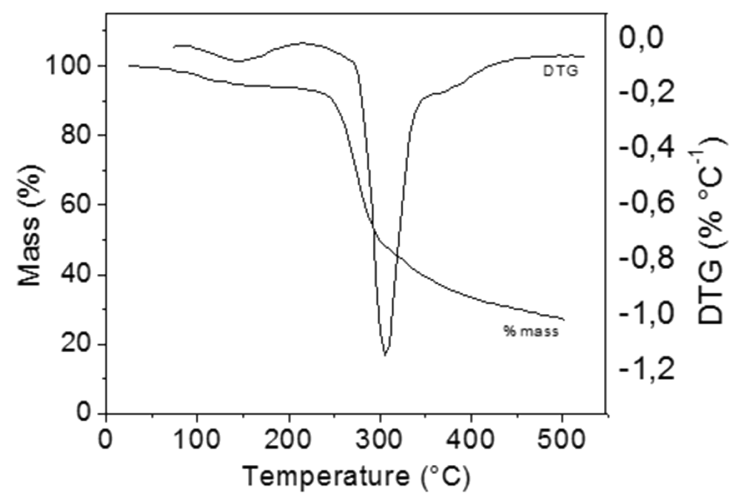

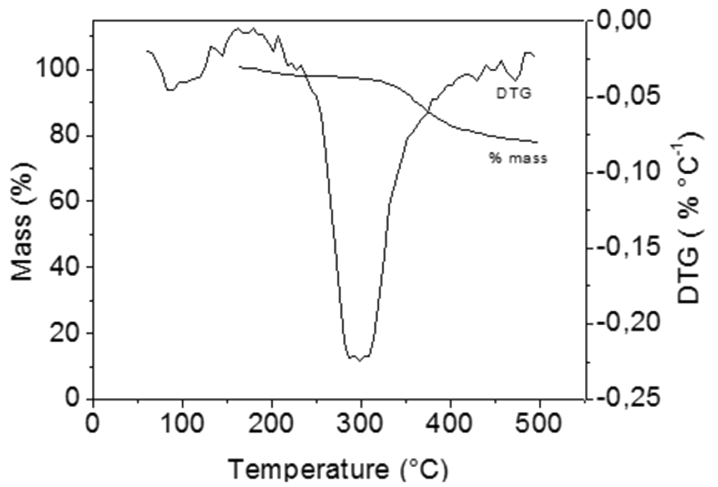

(b)

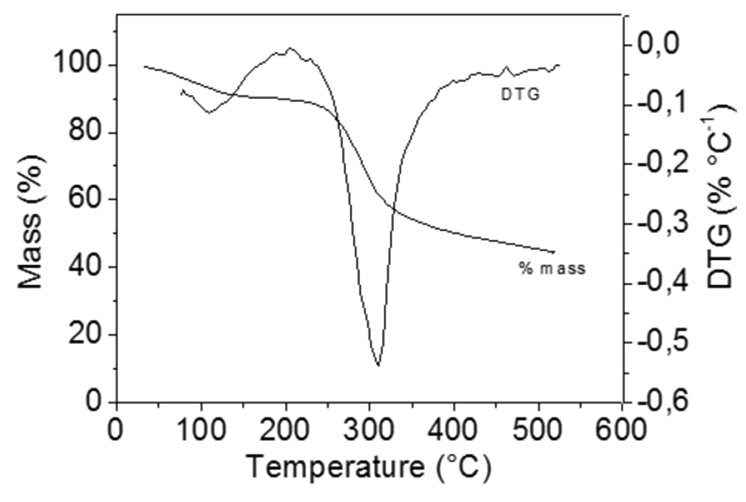

(d)

(c)

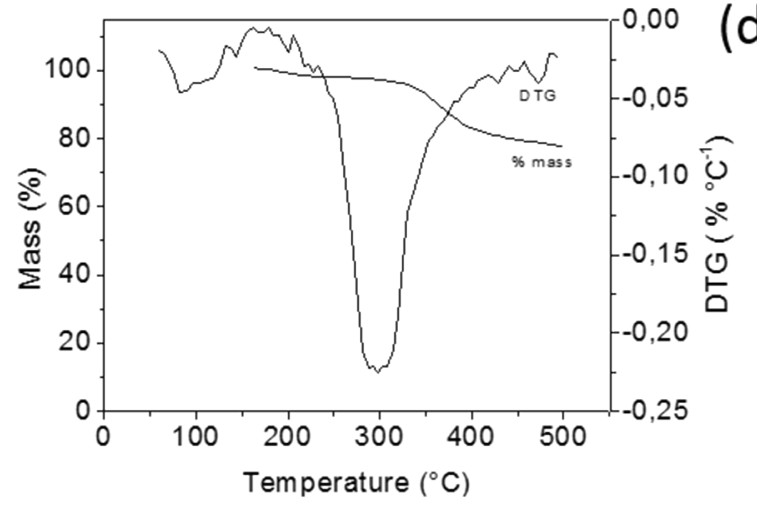

(e)

Figure 5. Termogravimetric analysis (TG) and Derivative TG curves of (a) CS-GP,(b) CS-GP-GA, (c) free lipase(d) lipase immobilized by physical adsorption (PA), and (e) lipase immobilized by covalent attachment (CA).

Table 1. Activities of free and immobilized lipases at different substrate concentrations. Kinetic parameters $\left(\mathrm{k}_{\mathrm{m}}\right.$ and $\left.\mathrm{V}_{\max }\right)$ of free and immobilized lipase. Catalytic efficiency and variation $\left(\mathrm{R}^{2}\right)$.

\begin{tabular}{ccccc}
\hline Lipase & $\begin{array}{c}\mathrm{k}_{\mathrm{m}} \\
(\mathrm{mM})\end{array}$ & $\begin{array}{c}\mathrm{V}_{\max } \\
(\mathrm{U} / \mathrm{g})\end{array}$ & $\begin{array}{c}\text { Catalytic efficiency } \\
\left(\mathrm{V}_{\max } / \mathrm{K}_{\mathrm{m}}\right)\end{array}$ & $\mathrm{R}^{2}$ \\
\hline Free lipase & 1153.1 & 21113.2 & 18.31 & 0.98 \\
Immobilized by PA & 2806.4 & 638.2 & 0.23 & 0.97 \\
Immobilized by CA & 771 & 369.4 & 0.48 & 0.94 \\
\hline
\end{tabular}


zeta potential of substrate, thus leading to change of electric attraction between enzyme and substrate ${ }^{30}$.

As expected, $\mathrm{V}_{\max }$ values for the immobilized lipases were reduced from $\mathrm{V}_{\max } 21113.2 \pm 1907.5 \mathrm{U} / \mathrm{g}$ for the free lipase to $638.2 \pm 131.6 \mathrm{U} / \mathrm{g}$ and $369.4 \pm 41.7 \mathrm{U} / \mathrm{g}$ for the lipases immobilized by PA and CA, respectively. This behavior can be attributed to the agglomeration formed by small hydrogel particles imposing diffusion limitations between biocatalyst and substrate. Changes on the enzyme microenvironment due to action of the GA crosslink agent could be also interfere the reaction rate of the lipase immobilized by $\mathrm{CA}$.

The catalytic efficiency is a cumulative factor expressed by the ratio of $\mathrm{V}_{\max }$ to $\mathrm{K}_{\mathrm{m}}$. Both immobilized lipases showed lower values of catalytic efficiency compared with the free lipase (Table 1). Between the immobilized biocatalysts, the lipase immobilized by CA was 2 times more efficient than the lipase immobilized by PA.

\subsection{Effect of $\mathrm{pH}$ and temperature on the activity of free lipase and lipase immobilized by $P A$ and $C A$}

A experimental designwas performed to attain the optimal conditions of $\mathrm{pH}\left(\mathrm{X}_{1}\right)$ and temperature $\left(\mathrm{X}_{2}\right)$ for hydrolytic activities of both free and immobilized lipases. For the lipase immobilized by PA, a full factorial design was used while for free and lipase immobilized by CA, star points were inserted to compose a second order model.

The experimental design is shown in Table 2, along with the experimental results. Free lipase and lipase immobilized by CA showed the highest lipolytic activities, $17682.97 \pm 1482.41$ $\mathrm{U} \mathrm{g}^{-1}$ and $547.04 \pm 16.65 \mathrm{U} \mathrm{g}^{-1}$, respectively at the central point ( $\mathrm{pH} 7.5$ and $50^{\circ} \mathrm{C}$ ), while lipase immobilized by CA attained $575.45 \pm 10.79 \mathrm{Ug}^{-1}$ at highest level point $(\mathrm{pH} 8.5$ and $60^{\circ} \mathrm{C}$ ). These results suggest that an increase of $56.8 \%$ occured in the lipase activity after the combination of variations in the $\mathrm{pH}$ and temperature. For the free lipase an increase of $24.3 \%$ and $41.6 \%$ for immobilized lipase by $\mathrm{CA}$ and $\mathrm{PA}$, respectively.

The individual effects and variable interactions $(\mathrm{pH}$ and temperature) in the hydrolitic activities for free and immobilized lipases were estimated with aid of Statistica 7.0 , considering a confidence level of $95 \%$, significance $\mathrm{p} \leq$ 0.05 and Fisher's statistical test for analyzis of variance. The models were checked by the $\mathrm{R}^{2}$, which indicates the value of sample variation for hidrolytic activities attributed to the studied variables. The results obtained from the statistical studies were shown in Table 3.

According to the Student's T test, both variablesshowed negative and significant quadratic effects for the free and

Table 2. Experimental design and hidrolytic activity obtained for different combination of $\mathrm{pH}$ and temperature.

\begin{tabular}{cccccc}
\hline Tests & $\begin{array}{c}\text { Real variable (coded variable) } \\
\mathrm{pH}\end{array}$ & $\begin{array}{c}\text { Hidrolytic Activity }(\mathrm{U} / \mathrm{g}) \\
\text { Temperature }\left({ }^{\circ} \mathrm{C}\right)\end{array}$ & Free Lipase & Immobilized PA & Immobilized CA \\
\hline 1 & $6.5(-1)$ & $60(+1)$ & $15565.25 \pm 2011.84$ & $149.32 \pm 4.84$ & $329.78 \pm 33.89$ \\
2 & $6.5(-1)$ & $40(-1)$ & $7359.08 \pm 105.89$ & $100.02 \pm 2.83$ & $76.13 \pm 21.44$ \\
3 & $8.5(+1)$ & $60(+1)$ & $8788.54 \pm 317.66$ & $575.45 \pm 10.79$ & $70.33 \pm 8.97$ \\
4 & $8.5(+1)$ & $40(-1)$ & $12388.67 \pm 741.20$ & $542.40 \pm 4.28$ & $328.89 \pm 24.74$ \\
5 & $7.5(0)$ & $50(0)$ & $15988.80 \pm 423.54$ & $486.11 \pm 7.68$ & $423.28 \pm 10.08$ \\
6 & $7.5(0)$ & $50(0)$ & $17682.97 \pm 1482.41$ & $529.13 \pm 6.84$ & $547.04 \pm 16.65$ \\
7 & $7.5(0)$ & $50(0)$ & $16253.51 \pm 1005.92$ & $434.69 \pm 7.73$ & $482.41 \pm 7.70$ \\
8 & $6.1(-\alpha)$ & $50(0)$ & $11012.15 \pm 635.32$ & - & $253.38 \pm 45.13$ \\
9 & $8.9(+\alpha)$ & $50(0)$ & $12759.27 \pm 1279.63$ & - & $186.71 \pm 13.40$ \\
10 & $7.5(0)$ & $36(-\alpha)$ & $12176.90 \pm 1270.63$ & - & $248.83 \pm 20.19$ \\
11 & $7.5(0)$ & $64(+\alpha)$ & $5664.91 \pm 158.83$ & & $146.03 \pm 40.78$ \\
\hline
\end{tabular}

Table 3. Estimation of the effects of variables, standard error and the p value for the hydrolytic activity of free lipase and immobilized by PA and CA.

\begin{tabular}{cccccccccc}
\hline & \multicolumn{3}{c}{ Free Enzyme } & \multicolumn{3}{c}{ Immobilized by PA } & \multicolumn{3}{c}{ Immobilized by CA } \\
\cline { 2 - 11 } Variable & Effect & $\begin{array}{c}\text { Standard } \\
\text { Error }\end{array}$ & $\mathrm{p}$ & Effect & $\begin{array}{c}\text { Standard } \\
\text { Error }\end{array}$ & $\mathrm{p}$ & Effect & $\begin{array}{c}\text { Standard } \\
\text { Error }\end{array}$ & $\mathrm{p}$ \\
\hline Média & 16631.77 & \pm 526.11 & $0.0100^{*}$ & 341.79 & \pm 23.64 & $0.0048^{*}$ & 484.27 & \pm 35.73 & $0.0054^{*}$ \\
$\mathrm{X}_{1}$ (Linear) & 176.48 & \pm 647.69 & 0.8108 & 434.26 & \pm 47.28 & $0.0116^{*}$ & -25.26 & \pm 43.99 & 0.6238 \\
$\mathrm{X}_{1}$ (Quadratic) & -4460.76 & \pm 777.49 & $0.0291^{*}$ & & & & -270.56 & \pm 52.81 & $0.0360^{*}$ \\
$\mathrm{X}_{2}$ (Linear) & -1139.08 & \pm 647.69 & 0.2207 & 41.18 & \pm 47.28 & 0.4757 & -37.58 & \pm 43.99 & 0.4829 \\
$\mathrm{X}_{2}$ (Quadratic) & -7486.07 & \pm 777.49 & $0.0106^{*}$ & & & & -293.63 & \pm 52.80 & $0.0308^{*}$ \\
$\mathrm{X}_{1} \mathrm{X}_{2}$ & -5903.15 & \pm 911.38 & $0.0230^{*}$ & -8.13 & \pm 47.28 & 0.8794 & -256.14 & \pm 61.90 & 0.0537 \\
\hline
\end{tabular}


lipase immobilized by CA and interaction was significant only for free enzyme within the experimental range studied at a $95 \%$ ofconfidence level (Table 3 ). At the same confidence level, the lipase immobilized by PA showed only significant linear effect for the variable $\mathrm{pH}$.

From these results, statistical models could be composed with the coefficients correspondent to the significant effects. For the lipase immobilized by CA a linear model was fitted as no significant value was given by checking the curvature $(p=0.059)$. The coefficients related to non significant effects were excluded from the model, except when it was necessary to maintain hierarchy ${ }^{31}$. The models are given in Table 4.

The statistical significance of these models was evaluated by the $\mathrm{F}$ test (Table 4 ), which revealed that they were significant at $95 \%$ confidence level, without lack of fit. Also, the determination coefficient $\left(\mathrm{R}^{2}\right)$ indicates that the modelscan explain more $80 \%$ of the variability. Thus, the fitted equations were considered adequate for describing the activity as a function of the studied variables and were used to plot the response surfaces as shown in Figure 6 (a-c).

By considering the adjusted models, optimized conditions determined for each evaluated system were: free enzyme (48.8 ${ }^{\circ} \mathrm{C}$ and $\left.\mathrm{pH} 7.6\right)$; immobilized lipase by $\mathrm{PA}\left(60^{\circ} \mathrm{C}\right.$ and $\mathrm{pH} 8.5)$ and immobilized lipase by $\mathrm{CA}\left(49.5^{\circ} \mathrm{C}\right.$ and $\left.\mathrm{pH} 7.5\right)$.

Upon immobilization process, optimum temperature values were incresead due to the interaction between the enzyme and the surface support that can result in a more rigid structure for the protein molecule, resulting in a more stable active globular form of the biocatalystat higher temperatures.

To confirm these models, assays were carried out under the established conditions and the differences between the experimentaland theoretical values were lower than $5 \%$.

\subsection{Thermal and storage stability of the lipases immobilized by $P A$ and $C A$}

Aiming to evaluate the irreversible loss of enzymatic activity on exposure to high temperature, in this case $60^{\circ} \mathrm{C}$, the thermal stability of free and immobilized lipases was determined. The profile of thermal deactivation is illustrated in Figure 7. As expected, the immobilization process stabilized

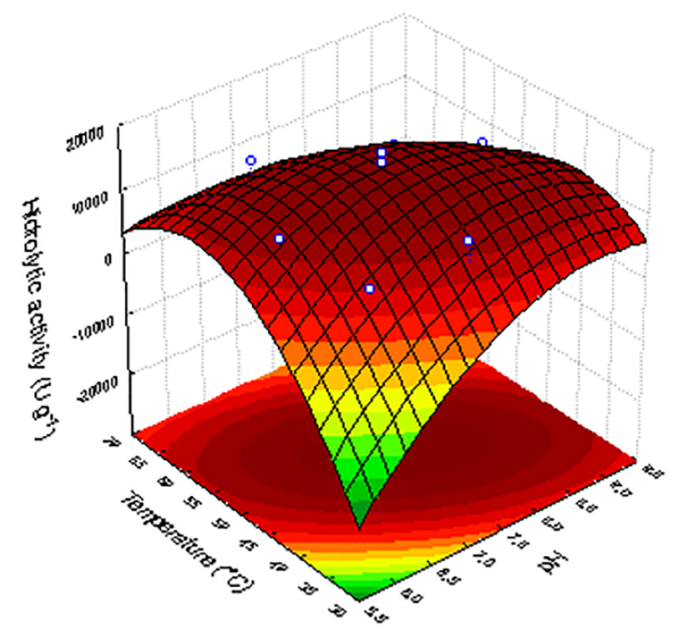

(a)

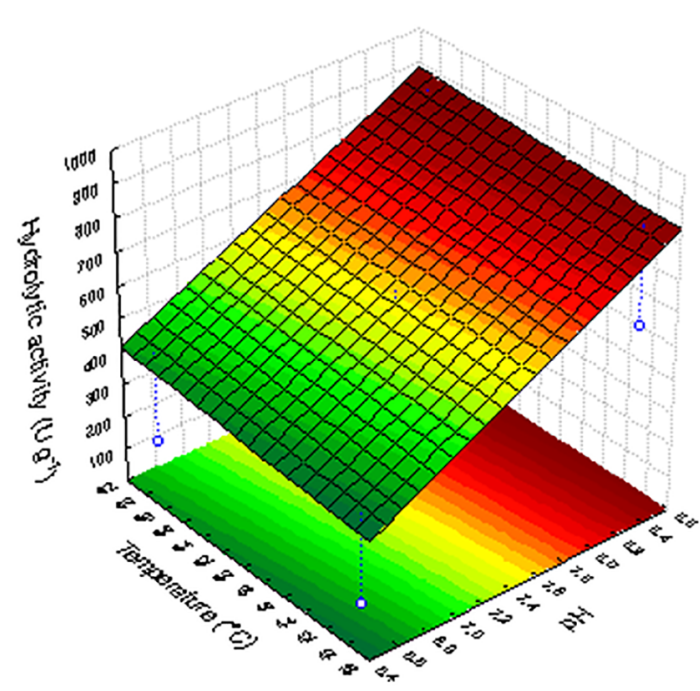

(b)

Figure 6. Response surface for: (a) free lipase, (b) lipase immobilized lipase by physical absorption (PA), and (c) lipase immobilized by covalent attachment (CA).

Table 4. Analysis of variance of the model that represents the hydrolytic activity of free lipase as function of $\mathrm{pH}\left(\mathrm{X}_{1}\right)$ and temperature $\left(\mathrm{X}_{2}\right)$.

\begin{tabular}{cccccccccccccc}
\hline & \multicolumn{4}{c}{ Free lipase } & \multicolumn{4}{c}{ Immobilized lipase by CA } & \multicolumn{3}{c}{ Immobilized lipase by PA } \\
\cline { 2 - 7 } & $\mathrm{SS}$ & $\mathrm{DF}$ & $\mathrm{F}$ & $\mathrm{p}$ & $\mathrm{SS}$ & $\mathrm{DF}$ & $\mathrm{F}$ & $\mathrm{p}$ & $\mathrm{SS}$ & $\mathrm{DF}$ & $\mathrm{F}$ & $\mathrm{p}$ \\
\hline $\mathrm{X}_{1}(\mathrm{~L})$ & 61665 & 1 & 0.0742 & 0.8108 & 188577.4 & 1 & 84.3517 & $0.0117^{*}$ & 1263.3 & 1 & 0.3297 & 0.6238 \\
$\mathrm{X}_{1}(\mathrm{Q})$ & 27341476 & 1 & 32.9175 & $0.0291^{*}$ & & - & - & - & 100576.8 & 1 & 26.249 & $0.0365^{*}$ \\
$\mathrm{X}_{2}(\mathrm{~L})$ & 2569044 & 1 & 3.0930 & 0.2207 & 1695.4 & 1 & 0.7583 & 0.4757 & 2796.8 & 1 & 0.7299 & 0.4829 \\
$\mathrm{X}_{2}(\mathrm{Q})$ & 77003800 & 1 & 92.7080 & $0.0106^{*}$ & & - & - & - & 118465.9 & 1 & 30.9177 & $0.0308^{*}$ \\
$\mathrm{X}_{1} \mathrm{X}_{2}$ & 34847180 & 1 & 41.9539 & $0.0230^{*}$ & 66.0 & 1 & 0.0295 & 0.8794 & 65589.8 & 1 & 17.1179 & 0.0537 \\
Lack of fit & 27265712 & 3 & 10.9421 & 0.0849 & 34329.9 & 1 & 15.3560 & 0.0594 & 3470.1 & 3 & 0.3019 & 0.8260 \\
Pure error & 1661213 & 2 & & & 4471.2 & 2 & & & 7663.3 & 2 & & & \\
Total SS & 151525162 & 10 & & & 229139.9 & 6 & & & 251518.4 & 10 & &
\end{tabular}




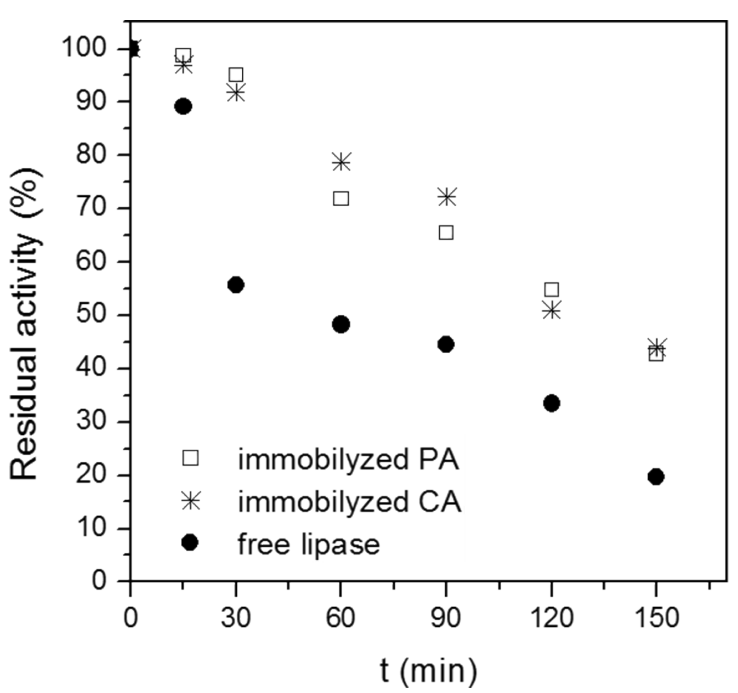

Figure 7. Thermal deactivation for: (square) free lipase, (star) lipase immobilized by physical absorption (PA), and (sphere) lipase immobilized by covalent attachment (CA).

the enzyme, since free lipase maintain only $20 \%$ of its original activity after an incubation period of $150 \mathrm{~min}$, while the immobilized enzyme by PA and CA remained $40 \%$ and $45 \%$, respectively, of their original activities. This behavior is in accordance with the results obtained by TG curves that indicated an enhancement in the thermal stability of lipase after immobilization.

Based on these results, the thermal deactivation constant $\left(\mathrm{k}_{\mathrm{d}}\right)$ and half-life time of free and immobilized lipases was determined by fitting a model of first order deactivation. The half-life time $\left(t_{1 / 2}\right)$ is the time which takes for the activity to reduce to a half of the original activity and inversely proportional to the rate of denaturation $\left(\mathrm{k}_{\mathrm{d}}\right)$. The results present in Table 5 reveal that the model adjusted to the results $\left(\mathrm{R}^{2}>0.97\right)$ and showed that both immobilized lipases were about 2 times more stable than the free lipase.

Table 5. Thermal inactivation constant $\left(\mathrm{k}_{\mathrm{d}}\right)$ and half-life of free and immobilized lipases.

\begin{tabular}{lccc}
\hline & $\mathrm{t}_{1 / 2}(\mathrm{~h})$ & $\mathrm{k}_{\mathrm{d}}\left(\mathrm{h}^{-1}\right)$ & $\mathrm{R}^{2}$ \\
\hline Free lipase & 0.98 & 0.70 & 0.97 \\
Immobilized by PA & 1.9 & 0.37 & 0.98 \\
Immobilized by CA & 2.0 & 0.35 & 0.99 \\
\hline
\end{tabular}

This improvement in thermal stability was also reported by Fernandes et al., (2014) $)^{27}$ and Silva et al. (2012) ${ }^{32}$. They obtained an increase of 25 and $80 \%$ using lipase from Candida antarctica immobilized on hydrogel and PHBV, respectively. Da Ros et al., (2010) ${ }^{33}$ immobilized the lipase from Bulkoderia cepacia on $\mathrm{SiO}_{2}$-PVA and $\mathrm{Nb}_{2} \mathrm{O}_{5}$ and found an increase half-life of 17 and 7 times respectively, while Silva et al., (2011) ${ }^{26}$ immobilized the same lipase on epoxy $\mathrm{SiO}_{2}$ chitosanand found a 30 times increase.
At low temperature, both the immobilized derivatives showed good storage stability, since after 120 days they retained $80 \%$ (immobilized by $\mathrm{CA}$ ) and $70 \%$ (immobilized by PA) of its original activity, as can be observed in Figure 8 .

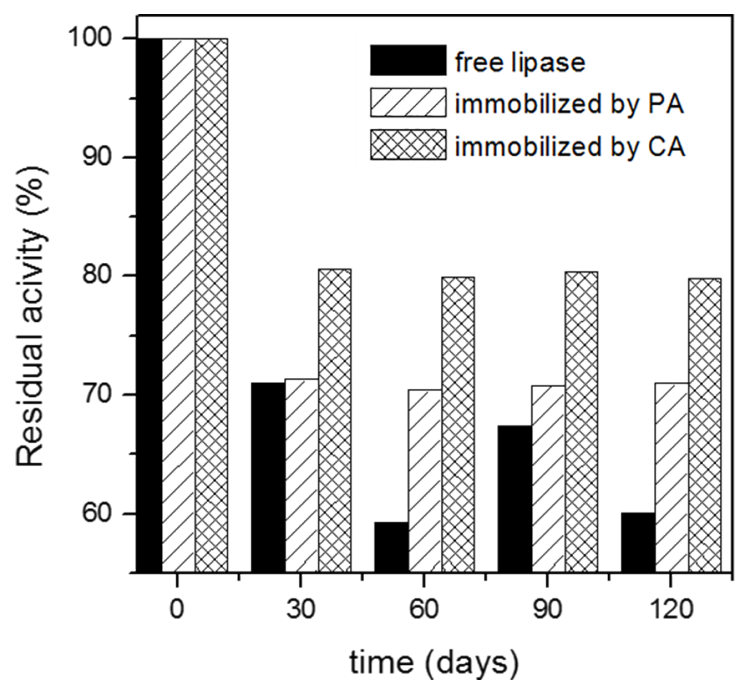

Figure 8. Storage stability for: (black) free lipase, (striped) lipase immobilized by physical absorption (PA), and (plaid) lipase immobilized by covalent attachment (CA).

\section{Conclusions}

The incorporation of the enzyme on the support took place differently depending on the method used. The immobilization by PA happened by the entrapment of lipase between the ionic bonds of chitosan and GP while CA occurred by bindings between the free aldehyde groups and amino groups $\left(\mathrm{NH}_{2}\right)$ of the lipase. The addition of glutaraldehyde caused a modification both on the surface of the support making it more compact, dense and less porous as in the structure that assumed a three-dimensional conformation. As a result, there was a greater affinity of the enzyme for this support CS-GP-GA and the thermal decomposition of the CS-GPGA support and the lipase immobilized by CA occurred in three stages and not in two as occurred in all other cases. The value of $\mathrm{V}_{\max }$ was negatively affected by the particle agglomeration of the support that made diffusion difficult in both immobilizations. In addition, an interdependence between $\mathrm{pH}$ and temperature was noted, since activity values were higher when compared to the activity of these variables alone. Finally, immobilization improved the enzyme stability as it exhibited a greater hydrolytic activity compared to the free enzyme after $150 \mathrm{~min}$. Therefore, CS-GP supports can potentially be used for lipase immobilization, and the CA method presented the best performance.

\section{Acknowledgements}

The authors thank the financial support from CAPES (Coordenação de Aperfeiçoamento de Pessoal de Nível 
Superior) and FAPEMIG (Fundação de Amparo à Pesquisa de Minas Gerais).

\section{References}

1. Berger J, Reist M, Mayer JM, Felt O, Peppas NA, Gurny R. Structure and interactions in covalently and ionically crosslinked chitosan hydrogels for biomedical applications. European Journal of Pharmaceutics and Biopharmaceutics. 2004;57(1):19-34.

2. Lee M, Li W, Siu RK, Whang J, Zhang X, Soo C, et al. Biomimetic apatite-coated alginate/chitosan microparticles as osteogenic protein carriers. Biomaterials. 2009;30(30):6094-6101.

3. Nagahama H, Maeda H, Kashiki T, Jayakumar R, Furuike T, Tamura H. Preparation and characterization of novel chitosan/ gelatin membranes using chitosan hydrogel. Carbohydrate Polymers. 2009;76(2):255-260.

4. Sung JH, Hwang MR, Kim JO, Lee JH, Kim YI, Kim JH, et al. Gel characterisation and in vivo evaluation of minocycline-loaded wound dressing with enhanced wound healing using polyvinyl alcohol and chitosan. International Journal of Pharmaceutics. 2010;392(1-2):232-240.

5. Tang C, Yin L, Yu J, Yin C, Pei Y. Swelling behavior and biocompatibility of Carbopol-containing superporous hydrogel composites. Journal of Applied Polymer Science. 2007;104(5):2785-2791.

6. Zhou Y, Zhao Y, Wang L, Xu L, Zhai M, Wei S. Radiation synthesis and characterization of nanosilver/gelatin/carboxymethyl chitosan hydrogel. Radiation Physics and Chemistry. 2012;81(5):553-560.

7. Zhou HY, Jiang LJ, Cao PP, Li JB, Chen XG. Glycerophosphatebased chitosan thermosensitive hydrogels and their biomedical applications. Carbohydrate Polymers. 2015;117:524-536.

8. Mendes AA, de Oliveira PC, de Castro HF, Giordano RLC. Aplicação de quitosana como suporte para a imobilização de enzimas de interesse industrial. Química Nova. 2011;34(5):831-840.

9. Wu J, Zhou T, Liu J, Wan Y. Injectable chitosan/dextranpolylactide/glycerophosphate hydrogels and their biodegradation. Polymer Degradation and Stability. 2015;120:273-282.

10. Thevarajah JJ, Van Leeuwen MP, Cottet H, Castignolles P, Gaborieau M. Determination of the distributions of degrees of acetylation of chitosan. International Journal of Biological Macromolecules. 2017;95:40-48.

11. Krajewska B. Application of chitin- and chitosan-based materials for enzyme immobilizations: a review. Enzyme and Microbial Technology. 2004;35(2-3):126-139.

12. Altinkaynak C, Tavlasoglu S, Özdemir N, Ocsoy I. A new generation approach in enzyme immobilization: Organic-inorganic hybrid nanoflowers with enhanced catalytic activity and stability. Enzyme and Microbial Technology. 2016;93-94:105-112.

13. İspirli Doğaç Y, Deveci İ, Mercimek B, Teke M. A comparative study for lipase immobilization onto alginate based composite electrospun nanofibers with effective and enhanced stability. International Journal of Biological Macromolecules. 2017;96:302-311.
14. de Paula AV, Nunes GFM, de Castro HF, dos Santos JC. Assessing the reaction conditions to mediate the milkfat-soybean oil enzymatic interesterification. Brazilian Journal of Food Technology. 2016;19:e2015116.

15. Soares CMF, de Castro HF, de Moraes FF, Zanin GM. Characterization and utilization of Candida rugosa lipase immobilized on controlled pore silica. Applied Biochemistry and Biotechnology. 1999;79(1):745-757.

16. Stuart BH, George B, Mcintyre P. Modern Infrared Spectroscopy. Chichester: John Wiley \& Sons; 1996.

17. Taqieddin E, Amiji M. Enzyme immobilization in novel alginate-chitosan core-shell microcapsules. Biomaterials. 2004;25(10):1937-1945.

18. Cho J, Heuzey MC, Bégin A, Carreau PJ. Chitosan and glycerophosphate concentration dependence of solution behaviour and gel point using small amplitude oscillatory rheometry. Food Hydrocolloids. 2006;20(6):936-945.

19. Chenite A, Chaput C, Wang D, Combes C, Buschmann $\mathrm{MD}$, Hoemann CD, et al. Novel injectable neutral solutions of chitosan form biodegradable gels in situ. Biomaterials. 2000;21(21):2155-2161.

20. Lowry OH, Rosebrough NJ, Farr AL, Randall RJ. Protein measurement with the Folin phenol reagent. The Journal of Biological Chemistry. 1951;193(1):265-275.

21. Xie W, Zang X. Immobilized lipase on core-shell structured $\mathrm{Fe}_{3} \mathrm{O}_{4}$-MCM-41 nanocomposites as a magnetically recyclable biocatalyst for interesterification of soybean oil and lard. Food Chemistry. 2016;194:1283-1292.

22. Beppu MM, Vieira RS, Aimoli CG, Santana CC. Crosslinking of chitosan membranes using glutaraldehyde: Effect on ion permeability and water absorption. Journal of Membrane Science. 2007;301(1-2):126-130.

23. Balevicius $\mathrm{Z}$, Ignatjeva D, Niaura G, Ignatjev I, Vaicikauskas $\mathrm{V}$, Babonas GJ, et al. Crowding enhances lipase turnover rate on surface-immobilized substrates. Colloids and Surfaces B: Biointerfaces. 2015;131:115-121.

24. Li W, Shen H, Ma M, Liu L, Cui C, Chen B, et al. Synthesis of ethyl oleate by esterification in a solvent-free system using lipase immobilized on PDMS-modified nonwoven viscose fabrics. Process Biochemistry. 2015;50(11):1859-1869.

25. Pang J, Zhou G, Liu R, Li T. Esterification of oleic acid with methanol by immobilized lipase on wrinkled silica nanoparticles with highly ordered, radially oriented mesochannels. Materials Science and Engineering: C. 2016;59:35-42.

26. Silva GS, Oliveira PC, Giordani DS, de Castro HF. Chitosan/ siloxane hybrid polymer: synthesis, characterization and performance as a support for immobilizing enzyme. Journal of the Brazilian Chemical Society. 2011;22(8):1407-1417.

27. Fernandes IA, Nyari NLD, de Oliveira JV, Rigo E, de Souza MCM, Gonçalves LRB, et al. Nanoparticles of poly(hydroxybutyrateco-hydroxyvalerate) as support for the immobilization of Candida antarctica lipase (Fraction B). Química Nova. 2014;37(2):331-336. 
28. Badgujar KC, Bhanage BM. Lipase immobilization on hyroxypropyl methyl cellulose support and its applications for chemo-selective synthesis of $\beta$-amino ester compounds. Process Biochemistry. 2016;51(10):1420-1433.

29. Chang SW, Shaw JF, Yang KH, Chang SF, Shieh CJ. Studies of optimum conditions for covalent immobilization of Candida rugosa lipase on poly $(\gamma$-glutamic acid) by RSM. Bioresource Technology. 2008;99(8):2800-2805.

30. Cipolatti EP, Valério A, Ninow JL, de Oliveira D, Pessela BC. Stabilization of lipase from Thermomyces lanuginosus by crosslinking in PEGylated polyurethane particles by polymerization: Application on fish oil ethanolysis. Biochemical Engineering Journal. 2016;112:54-60.
31. Myres RH, Montgomery DC. Response Surface Methodology: Process and Production Optimization Using Designed Experiments. Hoboken: Wiley; 1995.

32. Silva JA, Macedo GP, Rodrigues DS, Giordano RLC, Gonçalves LRB. Immobilization of Candida antarctica lipase B by covalent attachment on chitosan-based hydrogels using different support activation strategies. Biochemical Engineering Journal. 2012;60:16-24

33. Da Rós PCM, Silva GAM, Mendes AA, Santos JC, de Castro HF. Evaluation of the catalytic properties of Burkholderia cepacia lipase immobilized on non-commercial matrices to be used in biodiesel synthesis from different feedstocks. Bioresource Technology. 2010;101(14):5508-5516. 